\title{
EPISTEMOLOGY AND RATIONALITY OF INTUITION AND IMAGINATION IN THE FIELD OF MATHEMATICS
}

\section{EPISTEMOLOGIA E RACIONALIDADE DA INTUIÇÃO E DA IMAGINAÇÃO NO CAMPO DA MATEMÁTICA}

\author{
José Carlos Cifuentes ${ }^{1}$ \\ Lucimar Donizete Gusmão
}

What science can achieve are not the things themselves, but the relations between things; outside these relations there is no knowable reality.

Henri Poincaré

Imagination invents more than things and dramas; invents new life, invents new mind; opens eyes that have new types of vision.

Gaston Bachelard

\begin{abstract}
This paper aims to contribute to the clarification of the role of mathematical intuition and imagination in the constitution of mathematical knowledge, evidencing its epistemological and procedural characteristics. For that, an "epistemology of intuition and imagination" in the field of mathematics is outlined (suggested) emphasizing the need to adopt a dynamic conception of mathematics. In this context, intuition and imagination present themselves as forms of mathematical experience that give access, through paths that are not purely logical, to mathematical knowledge. Its epistemological and rationality characteristics, a rational of a non-logical nature, are highlighted by several examples, resources for moving the ideas involved. The epistemological study of intuition and imagination also allows highlighting its ontology, constituted of more relations than objects. From the pedagogical point of view, we discuss the formative character of philosophical studies involving intuition and imagination, mainly related to creativity in mathematics.
\end{abstract}

Keywords: Mathematical knowledge; Mathematical experience; Epistemology of intuition and imagination; Creativity in mathematics.

Resumo: Este artigo visa contribuir ao esclarecimento do papel da intuição e da imaginação matemáticas na constituição do conhecimento matemático, evidenciando suas características epistemológicas e procedimentais. Para tanto, uma "epistemologia da intuição e da i maginação" no campo da matemática é esboçada (sugerida) enfatizando a necessidade de adotar uma concepção dinâmica de matemática. Nesse contexto, a intuição e a imaginação são apresentadas como formas de experiência matemática que dão acesso, através de caminhos não puramente lógicos, ao conhecimento matemático. Suas características epistemológicas e de racionalidade, um racional de natureza não lógica, são evidenciadas por meio de diversos exemplos, fontes que movimentam as ideias envolvidas. O estudo epistemológico da intuição e da imaginação permite também evidenciar

${ }^{1}$ Doctor in Mathematics, State University of Campinas - UNICAMP, Campinas, São Paulo, Brazil. Professor at the Department of Mathematics and at the Graduate Program in Science and Mathematics Instruction, Curitiba, Paraná, Brazil. E-mail: jccifa@gmail.com

${ }^{2}$ Doctor in Education for Science and Mathematics, State University of Maringá - UEM, Maringá, Paraná, Brazil. Professor of Mathematics at Paraná State Public School, Curitiba, Paraná, Brazil. E-mail: lucimar.gusmao@gmail.com 
sua ontologia, constituída esta mais de relações do que de objetos. Do ponto de vista pedagógico, discutimos o caráter formativo dos estudos filosóficos, envolvendo intuição e imaginação, principalmente relacionado com a criatividade em matemática.

Palavras-chave: Conhecimento matemático; Experiência matemática; Epistemologia da intuição e da imaginação; Criatividade em matemática.

\section{Introduction: intuition, imagination and "mathematical experience"}

The aim of this paper is to clarify the role of mathematical intuition and imagination in the constitution of mathematical knowledge, evidencing their epistemological and procedural characteristics.

Although the main subject of this study is the epistemology of intuition and imagination, it is necessarily accompanied by a discussion about the ontology of intuition and imagination, an ontology that the epigraphs of this paper, although referred to the field of science and life, also point to the field of mathematics. We will see, supported by representative examples, that the ontology with which the mathematical intuition and imagination are faced is an ontology of relations and not of objects, as Poincaré already envisioned for science.

In (GUSMÃO, 2018) was emphasized the importance to ascend the mathematical knowledge through processes that involve, besides the reason and logic, also the sensitivity in the field of mathematics, and which are related to intuition, imagination, spontaneity, freedom and creativity, aesthetics characteristics that are peculiar to the field of arts.

The aesthetic apprehension in the relation between mathematics and arts and other sciences, apprehension that is closely linked with "mathematical experience", lies in the "perception" of patterns, order, elegance, and harmony of the "objects" studied through their mutual relations. This harmony helps to interpret mathematically the nature and reality studied by those sciences and, in order to interpret them, it is fundamental to understand mathematics in a more broadly way, a mathematics in which are relevant, beyond reason and logic, intuition and imagination for the constitution of knowledge, considering them as forms of mathematical experience.

In this approach, we emphasize that mathematics itself reveals its aesthetic face by showing its relations with imagination, intuition and creativity. According to our understanding, mathematics in this broader form of understanding would also allow an epistemological treatment coming from the epistemology of arts, of this poetics transformed into epistemology. 
For a theoretical foundation of this perspective, we bring Gaston Bachelard (18841962) with his two strands, the "diurnal" and the "nocturnal", which provide us with subsidies to start thinking about the research problem, that is, the elaboration of an "epistemology of imagination and intuition" in the field of mathematics, translating the strength of Bachelard's "diurnal" epistemology for the analysis of his "nocturnal" poetics. It is in poetics where he places imagination and its creative potential.

The epistemological aspect of Bachelard's science is that of the "diurnal" philosophy of scientific, objective and logical thought, while its poetic strand of science is that of the "nocturnal" reverie of thought based on intuition, imagination and creative processes, the art itself, as already mentioned.

Henri Poincare (1854-1912) brings to the discussion intuition as a form of access to mathematical knowledge, contributing to the understanding of mathematics in an enlarged conception that goes beyond the purely rational/logical, conception that had already been preconized by Immanuel Kant (1724-1804) as we will see below.

Why intuition and imagination in the field of mathematics are so important for its epistemology? A first response can be taken from Kant in his "Critique of pure reason". Although it is not our focus to take care of Kantians ideas about mathematics, we have to revisit them because, as argued by Torres Alcaraz, "one may be at odds with him, but what we cannot do is leave unanswered the questions that he makes/devises" (2005, p. 3 , our translation [o.t. for short]).

Kant has always been the reference (positive or negative) to mathematical intuition, strongly based on Euclidean geometry conceived by mathematical thinkers in the late nineteenth and early twentieth centuries, such as Helmholtz, Riemann, Brouwer, Poincaré, Russell, among others. But can we still use the Kantian matrix to understand the processes of imagination and intuition in present-day mathematics, that is, a mathematics that incorporates, for example, non-Euclidean geometries? What is Kant's most important contribution to mathematics developed from the nineteenth century?

Torres Alcaraz (2005) gives us an indicative statement that Kant sees in mathematical propositions necessary truths, however, unlike Leibniz, he does not see in them analytical propositions or purely logical. In his view, mathematical propositions are not necessarily followed by analyzes of the concepts contained therein; they are synthetic, however, a priori.

According to Torres Alcaraz (2005), Kant, then, advances in the direction of thinking that there are propositions in mathematics that are not purely logical. It is what 
he calls synthetic a priori propositions, they are not purely analytic as Leibniz thought, neither synthetic a posteriori nor do they derive from these, since they do not come from experience, understood in the sense of the empiricism of the natural sciences. So the need to think of mathematical propositions as being synthetic a priori is because in this condition they allow one to combine logic with intuition. With this kind of proposition, Kant gives openness to mathematical intuition as being important, along with logic, for the access to mathematical knowledge.

What we must recover from the previous discussion is that synthetic a priori propositions are not a consequence of analysis, but of a construction. That is what Kant says according to Torres Alcaraz (2005), mathematics is synthetic because its results are obtained by constructing, mathematics is a priori because its constructions are not empirical. We will see, precisely, that the aspects of synthesis and construction permeate the processes connected with intuition and imagination.

To deal with an "epistemology of intuition and imagination" in mathematics is only possible by adopting a dynamic "living mathematics" conception, weaving the fabric of thought, a mathematics considered not only as a static and rigid body of knowledge, but as a dynamic form of thinking, as a mental activity (not in the cognitive sense but rather epistemic), as a process. From this point of view, we seek to move away from the belief that mathematics is purely logical and rational, with the rigidity of a formal and abstract thought. For Poincaré, "logic is not enough; the science of demonstration is not the whole science, and intuition must retain its role as a complement, it could almost be said as a counterweight or as an antidote to logic" (1995, p. 20, o.t.). According to Bachelard, "an intuition is not demonstrated, it is experienced. And one experiences experimenting by multiplying or even modifying the conditions of its use" (1999, p. 910, o.t.). Thus, Bachelard points out that mathematical intuition is more on the side of mathematical experience than of logical reasoning.

In this way, "it will be mathematics itself in its dynamicity, which involves beyond logic, imagination and intuition, which will allow the development of a philosophy of mathematics, in particular, an epistemology of imagination and intuition in mathematics" (GUSMÃO; FRANCO; CIFUENTES, 2017, p. 369, o.t.).

We must clarify that what we mean by epistemology is not the theory of knowledge in general, but, modernly, the theory of scientific knowledge; the twentiethcentury conception of epistemology in which scientific knowledge is conceived with its logical rationality, especially in the case of mathematics, but disregarding or minimizing 
other possible forms of knowledge that involve the dynamic processes connected with imagination and intuition. In this dynamism, intuition and imagination are actions and not just capacities.

The word "scientific", in "scientific knowledge", refers to science, method. The natural sciences, for example, physics and biology, have as their main tools observation and experimentation, since mathematics in this context can not be considered as experimental science, but it admits procedures in which one of the main tools is logic, and where imagination and intuition, also considered as possible forms of access to knowledge, are dynamic ways of observing and experiencing in mathematics or better still they are manifestations of what we might call "mathematical experience." When we intervene imagination and intuition in mathematics, in the form pointed out above, we are approaching mathematics from other sciences, especially from the empirical sciences, because those actions are forms of experience in mathematics, of course with their own characteristics that we will soon elucidate. When we speak of imagination and intuition as forms of access to mathematical knowledge, we also need to broaden the concept of rationality, beyond the limits that logic imposes.

Regarding a possible conceptualization of "mathematical experience", Poincaré's ideas enter into dialogue with Bachelard's ones when we find points of contact or convergence, especially with regard to his conceptions of science and his relation to mathematics. They support an "empiricist view" of mathematics, a mathematics which, like physics, for example, uses observations and experiments with mathematical objectrelations to conceptualize them, and in which intuition and imagination play a relevant role.

But before them, Leonhard Euler (1707-1783), one of the greatest mathematicians of the eighteenth century, a century in which there was an explosion of mathematical development guided by informal and intuitive procedures, and before it had been subjected to the logical "rigor" of the century, said:

It is doubtless paradoxical to attach great importance to observation in the part of mathematics known as pure mathematics, for ordinary opinion believes that observation should be restricted to physical objects. [...] However, in fact, the properties of numbers known today have for the most part been discovered by observation, and long before their truth has been confirmed by rigorous demonstrations (EULER apud PÓLYA, 1966, p. 25, o.t.).

We will conclude this introduction by noting that our way of accessing the epistemological and procedural features of intuition and imagination will be through discussion of several examples; provided they are properly selected and interpreted, they 
will be the bearers of the dynamic qualities of intuition and imagination in the field of mathematics, and in their dynamicity they propose to discuss their epistemological dimension in a broader understanding of mathematics. The examples, therefore, are the main methodological tools of the research, because they allow to move the ideas and to show their different facets within the dynamic conception of the proposed mathematics.

\section{Our initial hypotheses of the research: intuition versus discovery and imagination versus creation}

Given the above considerations, it is important to elucidate what we mean by intuition and imagination in the field of mathematics, in order to do so we begin the construction of these notions by placing the following "working hypotheses for research" as starting points for the discussion, hypotheses that we will justify with illustrative examples:

1) We propose to associate, firstly, the intuition with the discoveries. One discovers something that already exists, but one does not necessarily have immediate access to it. For example, knowing that regular polygons with small numbers of sides have some common properties, so we can "intuit" that regular polygons with a high number of sides also have the same property; "we discover" through intuition this property that already exists, but which we do not "see" immediately.

For Brunschvicg, "data of intuition are no longer used merely to facilitate reasoning; it is, in the expectation of the demonstration, an instrument of discovery" (1945, p. 475 , o.t.).

2) Regarding imagination, we propose to associate it with creation and invention. In the inventive process constructions are made, that is, something new is created that does not yet exist. It is a form of construction. To imagine is to create and it is a free act, but it is not arbitrary. Perhaps the main purpose of imagination is to "define" (delimit) a new object through its creation/construction. For example, one can imagine (create) geometrical objects of the "world" of 4 or 5 dimensions, extrapolating objects with 2 or 3 dimensions.

Therefore, in the search for understanding the notions of intuition and imagination, we seek diverse mathematical arguments and examples that somehow justify their theoretical qualities and their dynamicity in the process of mathematical thinking. It 
is in the movement of imagination and intuition that they will reveal to us their secrets; and the several examples given below, as already mentioned, will allow such movement.

Thus, trying to intuit how many diagonals have a regular polygon of $n$ sides, we first observe that in the simplest cases we have the following: a triangle has 0 diagonals, a square has 2 diagonals, a pentagon has 5 diagonals, a hexagon has 9 diagonals. There are indications that there is a formula that determines the number of diagonals in each case and we wish to "discover" this formula for the general case of $n$ sides.

To do so, we help our intuition by revealing the process, part of its rationality, to find systematically the relations that determine the number of diagonals in a generic case. This process consists of the following: first, by fixing a vertex, "we see/observe" that $n-$ 3 diagonals leaves (disregarding the vertex itself and the two consecutive ones); second, as this can be done with each vertex, we will have $n(n-3)$ diagonals; third, however, we note that in the previous stage each diagonal is repeated twice (considering the vertex of departure and arrival), which gives us finally, $\frac{n(n-3)}{2}$ diagonals at all.

The formula obtained for the number of diagonals gives us only a conjecture on the sought response, which must then be demonstrated by some logical method as pointed out by Euler and Brunschvicg.

With this process, which also involves a synthesis and selection of some relations of the discovered object, we have intuited the formula that determines the number of diagonals for any given convex polygon, a formula that can be corroborated in the simplest cases.

We also use this example to highlight some of the characteristics of this process of discovery by intuition.

First, intuition is different from perception; in fact, mathematical intuition is not a perception of the immediate, but it is a "visualization" (a kind of higher-order perception) of the general, although in the argumentative process one deals with a case called generic. This visualization of the general already reveals to us that what is being intuited is not the things themselves, but the relations that determine them, as thought by Poincaré. Intuiting the general, the universal, is precisely to capture the relations that govern the various particular cases and is a form of induction.

Now, in the case of the imagination, it will be associated, as already said, with the creation/construction of a new object. It, as we shall see, allows us to construct an object 
by generalization, a process which, as such, requires that the simplest cases that have motivated it be the particular cases.

For example, if we pose the problem of constructing a four-dimensional geometric "world", its objects could be defined in different ways, however, the choice of the "most adequate" definition will not be arbitrary and should be based on the characteristics of the corresponding objects in smaller dimensions. Let us see, for example, what will be the definition of what we will call a four-dimensional hyperplane. For this, we will be guided by the correspondents in dimensions two and three.

We ventured the idea that the corresponding to the four-dimensional hyperplane are the three-dimensional plane and the two-dimensional straight line.

In the two-dimensional case, the Cartesian equation of a straight line is of the form $a \mathrm{x}+b \mathrm{y}=c$, where $a, b$ and $c$ are constant real numbers. In the three-dimensional case, the Cartesian equation of a plane is of the form $a \mathrm{x}+b \mathrm{y}+c \mathrm{z}=d$, where $a, b, c$ and $d$ are real constants. The analogy suggests that in the four-dimensional case, the Cartesian equation (with 4 coordinates $\mathrm{x}, \mathrm{y}, \mathrm{z}$ and $\mathrm{w}$ ) should be as follows $a \mathrm{x}+b \mathrm{y}+c \mathrm{z}+d \mathrm{w}=e$, where $a, b, c, d$ and $e$ are real constants.

Thus, Cartesian formula for a four-dimensional hyperplane is not discovered, it is created based on the analogies that allow it to be configured, and it is not an arbitrary creation either, for analogy provides the rules of generalization. Here, too, are the relationships that determine the object/concept created/constructed. This example also shows us that imagining, in the sense we are adopting here, is not bringing an image to the mind, it is creating an abstract object through its conceptual determinations.

In mathematics, imagination and knowledge from the imagination, although not on the side of scientific objectivity, is not a trivial act, devoid of all rationality (see section 3.1). Imagination is not only the process of constructing or creating images, even abstract ones, it also involves, as in the case of intuition, the realization of syntheses in this creation.

This example will also show us that, once the object is constructed, intuition comes into play to allow us to discover other properties of this object that were not part of its initial constitutive relations. In addition, we can corroborate the coherence of the construction, a trace of its rationality.

For example, an important property that the plane in three-dimensional space and the straight line in two-dimensional space have is the following: they divide the spaceenvironment in which they lie in two disjointed parts, so that by joining with a segment 
of a line a point of one of the parts with another point of the other part, this segment must traverse the plane in the three-dimensional space or the straight line in the twodimensional space given. We let the reader see that this is true of the hyperplane.

In the same way, we can imagine that the vector of coordinates $a, b, c, d$, formed by the coefficients of the variables $\mathrm{x}, \mathrm{y}, \mathrm{z}$ and $\mathrm{w}$ in the hyperplane equation, signals the only direction perpendicular to the hyperplane, which can also be verified easily.

Analogous arguments can be made to construct, for example, hypercube and hypersphere in four-dimensional spaces (GUSMÃO, 2018).

From the point of view of the philosophy of science adapted to mathematics, to the extent that intuition has been placed on the side of discovery and imagination on the side of creation, this suggests that intuition assumes traces of realism and the imagination of antirealism, that is, the reality to be intuited is a priori while the reality to be imagined is a posteriori.

\section{Building an epistemology of intuition and imagination through examples}

In the history of mathematics we find many examples illustrating the role of intuition and imagination in the process of elaborating knowledge. The choice of examples, as well as pertinent arguments, becomes an important method of study and research, as we have already said, to justify the different conclusions, contributing, in turn, to a pedagogical discussion that could strengthen the role of mathematics in the teaching field and its different interdisciplinary relationships.

The imagination linked to the invention, as already said, allows to create something new, being, therefore, a free act. To that extent, your choices require the concurrence of intuition. With this, we are attributing to the imagination a characteristic that arts also has. Imagining/inventing/creating/building is an artistic process, not a logical reasoning.

On the other hand, one of the purposes of intuition is the elaboration of "conjectures", as already exemplified, whose consolidations as truths require a later logical demonstration.

Frequently we associate mathematical intuition with a knowledge that is somehow immediate, but we question this association, presenting examples in which intuition, as we conceive it, is not necessarily immediate, although it is not discursive. 
Let us consider, for example, the square numbers of Pythagoras: the sequence 1, $4,9,16, \ldots$ consists of the so-called perfect squares or squares (denomination which we still preserve) of the first positive integers.

It is through the geometric representation of these numbers, arranged spatially in the form of squares, given by Pythagoras (6th century b.J.C.), which makes possible their visualization. In this way it is possible to find and intuit some laws that govern the sequence. For example, in the case of the first square numbers one can see that each of them is the sum of the consecutive odd numbers starting at 1 , that is $1 ; 1+3 ; 1+3+5 ; 1$ $+3+5+7 ; \ldots$, which can be verified, in these first terms of the series, by its geometric configuration.

The geometric configuration "induces" us to conjecture that for all $n, n^{2}=1+3+$ $5+\ldots+(2 n-1)$; including the last term $(2 n-1)$ which is the product of synthesis and extrapolation.

Also, from this geometric representation one can see that the initial square numbers are the sum of two consecutive triangular numbers (class of numbers also studied by Pythagoras whose spatial arrangement is in the form of equilateral triangles): $1 ; 1+3$; $3+6 ; 6+10 ; \ldots$, which can be conjectured, from an act of induction, by intuition of all the terms of the series.

It is also possible to "predict" the next term of the sequence, that is, the term 25 , which involves another aesthetic characteristic of mathematics, the simplicity, which appeals to our ability to choose. The "next term of the sequence" among the multiple possibilities is the one whose choice is the simplest within a certain set of data contained in the previous terms of the sequence. Thus, it is perceived that intuition has as one of its characteristics the selectivity that, according to Ostrower (2010, p. 66), represents a process of economy. We tend to seek what would be enough to solve a particular situation in which we are involved. In fact, "sufficiency" in the choice of relations that delimit an object is one of the characteristics that intuition uses to establish its conclusions, unlike the logic that needs "necessity". Once again, intuition brings us into contact with the relational characteristics of objects.

According to Cifuentes:

An approach to mathematics taking into account its aesthetic aspects would enable the mathematics of error or imprecision to be developed, which could be regarded as mathematics of sufficiency, complementary to mathematics of necessity. The following example clarifies this concept: a certain finite number of terms of a sequence is enough to intuitively "visualize" its training rule or its limit (2005, p. 59, italics added, o.t.) 
Intuition allows us to see what is far away, that is, to predict. For Poincaré, intuition is the "faculty that makes us see the end from afar" (1995, p. 21). Moreover, "In order to predict, one must at least invoke the analogy, which is already generalized" (2008, p. 224-225). And in the sequence, he complements "every generalization presupposes belief in the unity and simplicity of nature. [...] Of course, a given fact can be generalized in a myriad of ways. The point is to choose. The choice can only be guided by considerations of simplicity" (2008, p. 227, o.t.).

These excerpts indicate that Poincaré's discovery takes place through analogy and generalization, as well as the synthesis as we have already seen, a synthesis that still resorts to selectivity and sufficiency, characteristics of the epistemology sought.

In the previous example, we wondered: how do we acquire the intuition that "all" these numbers (the universality from particular cases) are, for example, the sum of two triangular numbers? Observing the ways these numbers are configured in their sequentiality we realize that this process is not deductive but rather inductive and analogical. It is in the observation of the first square numbers that we perceive that the properties repeat themselves in the other configurations. However, it is not an observation in the individuality of each term of the sequence, but in the passage from one to the other (analogy), in the relation of one to another, which allows to conclude, or better to conjecture, by intuition, that all the square numbers have this property.

So there are two types of intuition in this case, the immediate intuition and the intuition that we will call generalizing. The latter is the intuition that allows us to "see far away". In immediate intuition it is possible to find the following sequence number, that is, we have the "intuition of the next" which, as we have seen, resorts to selectivity and simplicity in this process. Poincaré said that "to generalize we must choose"; and intuition "from far away" allows us to "see the whole" of the sequence in each of its terms, that is, we have the intuition of a totality, a universality, which characterizes the process of generalization. Moving from one term to another is immediate, but intuition in the distance becomes generalizing intuition, and for this process the analogy is one of the main ingredients.

For Poincaré, the intuition that allows us to "see" far away, is what happens, for example, in the game of chess: to find a sequence of moves that leads to success is not enough to know only the rules of the game, you need to have the intuition of the "right" move for far away. All that in an ontological relational framework. 
One of the characteristics of the discovery, then, through generalizing intuition is the structuring of a generality, of a universality, an important trait of the resulting ontology. It is "the character of the general in the particular", that is, it is not a concrete particular that is perceived by intuition, it is a generic particular, a particular that has a universal character.

From the epistemological point of view, intuition also suggests that the visualization of the objects reached by it occurs through its constituent relations, relations that relate to its form and not to its content or matter. Kant already announces, in other words, the relational ontology that we attribute to intuition when he speaks of "pure intuition", an intuition which, in his view, captures the "form" of the intuited object, forms ordered according to certain relations. In Kantian patterns, relations are then part of the form of the object and not of its matter.

Other examples can be given, notably the case of the various geometries.

In this context of intuition/discovery, imagination/creation (our working hypotheses) one can argue that, regarding the study of "space", Euclidean geometry, in Euclid's own version, is on the side of intuition, while non-Euclidean geometries are on the side of imagination.

To understand this distinction we must first consider what we call "geometry", a theory (usually presented in axiomatic form), which studies geometric space and speaks of certain objects as points, lines, planes, angles, and so on. These objects only acquire a "concrete" meaning in the studied geometric space, which we can call space of concretization (where these objects can be visualized somehow).

In the case of Euclidian geometry, as made by Euclid, the corresponding space is the "natural space" and it preexists to geometry, that is, Euclidean geometry is the study of the natural space. In this sense, the geometric properties of this space are apprehended by intuition. In this natural space, the visualization representation of the corresponding geometric objects can be given through its construction with ruler and compass, construction that often needs a certain degree of imagination.

As for non-Euclidean geometries, developed in the nineteenth century, they arise first as a logical axiomatic game (axioms, theorems, logical demonstrations) and there is no pre-determined non-Euclidean spaces. Such spaces are artificial creations to give a semantic (interpretative) support to these new geometries. These spaces are created later to provide these geometries with a space, or spaces of concreteness called models of these geometries. From this point of view, at first, they are products of the imagination. In a 
second moment, once constructed the non-Euclidean models, they already can serve to feed the intuition on other properties of these geometries. These models, once invented, become "natural" to these geometries and acts as the natural spaces similar to that of Euclidean geometry. Often, non-Euclidean geometry models are a logical creation from the Cartesian models of Euclidean geometries.

\subsection{The rationality of intuition and imagination}

The intelligibility of the "real" has two faces in which on one face we can put the logic that deals with the world of the permanent, and on the other the intuition and the imagination that deals with the world of fluid.

From this point of view, we understand that rationality is not only linked to logic. And to understand this fact we have resorted to two pre-Socratic philosophers/mathematicians who had a different but complementary view to understand these worlds: Parmenides and Heraclitus (6th-5th centuries b.J.C.).

a) The Apollonian world of Parmenides is characterized by permanence, absolute, perfection, truth, the logic of true and false, the rational, the quantitative, the unity. Knowledge of this world is objective and precise. Events are deterministic. Modernity, from the seventeenth century, expresses this conception of the world through Cartesian simplicity, simplicity metaphorically translated in the conception of the machine-world: the complexity of the machine is explained by the simplicity of its gears.

b) The Dionysian world of Heraclitus is characterized by transformation, generation and mutation, relative, uncertainty, imperfection, dialectic and rhetoric of the best and the worst, the irrational, the qualitative, the diversity. Knowledge of this world is subjective and imprecise. Events are nondeterministic. In postmodernity, already in the twentieth century, complexity, not reducible to the simple, is at the basis of the intelligibility and knowledge of this world.

From that, the world of Parmenides is traditionally associated with the unchangeable, the rational, the logical. Whereas the world of Heraclitus is associated to the irrational, the fluid, the imagination and the intuition. The world of Heraclitus is not opposed to that of Parmenides. There is a rationality in his world, a rationality of irrationality. It captures the unity in multiplicity, in movement, in transformation. A unit of dialectically opposite stresses. There is a hidden harmony of opposing forces that 
allows him to capture that rationality in his world, which allows him to grasp, formulate, and synthesize.

In this sense, regarding current mathematics, we can consider that there are different degrees and/or types of rationality for their proper understanding (which will have implications for their teaching), since this mathematics emphasizes abstraction and qualitative beyond quantitative, and incorporates the intuition and the imagination in its dynamic conception, necessitating, then, a new notion of rationality.

In addition to the rational patterns of logic, based on necessity, in order to understand this current mathematics, we must then consider other types of rationality, a rationality of imagination and intuition that we might call perhaps aesthetic rationality, whose principles will be topic of discussion.

According to Cifuentes,

\begin{abstract}
With Pythagoras and his contemporaries, a new way of contemplating the world is born: through reason. The "rational spirit" is born. From the point of view of reason, more important than to think that the universe was created by "God" is to think that it was created following certain principles that stimulate our reason. These principles shaped the logic of rationality. Human reason needs principles to work! $(2017$, p. 6 , o.t.)
\end{abstract}

Reason and intuition, as well as reason and imagination, are not dichotomist actions, both have similar characteristics, to create meanings and produce knowledge to establish what does not yet exist. In particular, for Bachelard, imagination is a creative, active, open, realizing (knowledge-producing) faculty. Imagination and intuition are actions that allow us to discover or construct paths, and in the ordering and structuring of these paths is their rationality. We can then formulate as a presupposition for our pursuit the following: intuition and imagination have a rationality that can provide subsidies for the organization and structuring of knowledge in mathematics through them.

To speak of an epistemology of intuition and imagination in the context of mathematics, where logic is traditionally sovereign, is almost a paradox, however, the rationality of imagination, of intuition, also involving the processes of creation, which is intended here put in evidence, enables the elaboration of this epistemology and the discovery of its principles in order to allow a better understanding of mathematics itself as a producer of knowledge and its role in mathematical education.

In the case of imagination, being a creative process and having a constructive dimension, it sets in motion mental capacities of association, configuration, ordering, harmony, synthesis, economy, etc., and this requires the non-arbitrary freedom mentioned above. In imagination, then, there is controlled freedom. Creating is a free act, but it is 
not arbitrary. Freedom has a certain rationality that goes beyond logic. However, the construction of the "object" given by the imagination is "good" insofar as it has "plausible consequences." It is a kind of inverse logic, and the search for these consequences can be guided by intuition and based on sufficiency rather than necessity, as already pointed out. Once the object is constructed, intuition will allow us to discover other properties of this object that were not part of its initial constitutive relations.

In the "ontology of imagination and intuition", which we call relational ontology, are the relations between objects, duly associated in a kind of plot, that give them existence.

Synthesis, combined with a kind of induction, is one of the main instruments of imagination and intuition to access this ontology and the constitution of knowledge. The resources of intuition and imagination, as well as those of arts, whether by discovery or invention, can only give us an appearance of reality in its multiplicity, but unified by a process of synthesis. One unit in multiplicity. Synthesis plays an essential non-logical role in the rationality of imagination and intuition.

The analogy feature is used for the creation/construction of knowledge by imagination, but the process of creation by analogy is not arbitrary, because it uses rules of "translation" that maintain a certain coherence. Analogies enable us to illustrate, visualize, explore relationships, and thus enable the construction of knowledge. The analogy establishes a comparison between one element considered familiar with another, at first unknown. Comparison, by analogy, allows us to construct, for example, new things in mathematics. It also allows for the development of abstract mathematical thinking and generalization. Exploitation by analogy leads to a certain harmony (coherence), and is therefore an essential element for the beauty of mathematics.

In the constitution of this epistemology of imagination and intuition we can not fail to highlight the role of hypotheses as triggers of constructions and discoveries in mathematics. This role is analogous to what happens, for example, in physics. In fact, for Poincaré, hypotheses have a fundamental function in science for the understanding of nature through the elaboration of theories, and for the understanding of mathematics itself through the composition of axiomatic systems. In physics, for example, the principle of inertia, originally formulated by Galileo, is the establishment of a hypothesis (in fact, unreal) for the development of later physical theory, a theory consolidated by Newton. In mathematics, hypotheses appear as axioms in axiomatic systems, and their condition of hypotheses is necessary for the possibility of not being obvious truths as in the case of 
non-Euclidean geometries. The scientific and mathematical theories in their rational elaboration also emerge as synthesis of a great quantity of facts that are related to each other, synthesis that is expressed through the hypotheses or of conjectures.

\section{Formative aspects of intuition and imagination for the mathematical thought}

The research presented here, although directed to the formation of the mathematician, is also pertinent to the formation of the mathematics teacher, and intends to clarify to what extent the philosophical, epistemological and pedagogical studies in the field of mathematics and mathematical education are "formative" of the mathematical spirit for a better understanding of this concept.

For Bachelard, formation (of the scientific spirit) implies essentially the deconstruction and reconstruction by which the subject must break with the epistemological and pedagogical obstacles, with the delays and pre-established conceptions that prevent him from reaching the knowledge. In this process, "spirit reveals itself as a being to be instructed, that is, as a being to be created. Knowledge is energized by its historicity. By having a history, he has a destiny. This history is pedagogical" (BACHELARD, 2008, p. 80, o.t.).

According to Barbosa and Bulcão (2004, p. 51, o.t.), the "problem of training in Bachelard develops from two distinct axes [...]: the axis of reason and the axis of the imagination". These two axes, which are in principle opposed to each other, contribute to the development of the human spirit and, why not to say, the scientific and mathematical spirit.

From the formative point of view, intuition and imagination can be mediators between thought and sensibility, between representation and abstraction. To imagine is the ability to see beyond the look, beyond the immediacy of beyond what is given, to create possibilities, new ideas, which are fundamental for creation in mathematics. Although the focus here is not the cognitive aspects of the imagination, but the epistemological ones. Imagination, like intuition, is a capacity that belongs to the subject, therefore, when it is stimulated it can contribute to the construction of knowledge and the understanding of its dynamicity, particularly in the teaching of mathematics.

Releasing the imagination is almost a playful necessity, like a game that allows us to play with the world. In this respect, we perceive an approximation between mathematics and arts. 
Mathematical constructions or models sometimes appear as toys, harmless, initiatory and curative, with which men can make their imagination work, give importance and a reason for being, build worlds sometimes baroque, unravel the ghosts that people their spirit and that they are liberated by the game (BRUTTER, 1998, p. 28, o.t.).

Thus, one learns mathematics by doing mathematics, that is, by "mathematizing". This is a form of artistic activity, for arts, like mathematics, can not be learned by precept, by any verbal instruction. Both are, properly speaking, a contagion, and transmitted as fire from spirit to spirit. "Sensitivity to beauty in math is contagious. It is contracted, not taught" (HUNTLEY, 1985, p. 18, o.t.). We can say, even if, on the one hand, mathematics, like philosophy, is knowledge, on the other hand, "mathematizing" is an art, just as philosophizing is!

\subsection{Visualization and creativity in mathematics as resources for the construction of mathematical knowledge}

The possibility of "seeing" objects discovered by intuition or created by imagination requires identifying an ontological space of "realization" of these objects. From this point of view, mathematics can be considered an empirical science such as physics, in which access to this ontological space can be done through mental observations or experiments with the objects therein. This ontological space will be the "space of mathematical experience", and visualization will be the form of access to it.

To access this space, one of the most modern tendencies in mathematics teaching is the visualization, especially the geometric one, making geometry more a point of view than a systematized subject. In this case, the problematic about the concretization of geometric objects-relations only makes sense in the conception of mathematics that incorporates imagination and intuition as part of the resources for the heuristic construction of mathematical knowledge, conception that considers mathematics as an activity, where dynamics of thought is manifested. In this heuristic construction of knowledge, we can speak of "observation" of mathematical objects or experimentation with them, a resource of empirical science within mathematics.

The emerging relational conception in the nineteenth and twentieth centuries is consolidated in the so-called mathematical structures. The structures capture the relations between the objects under study and not the objects themselves (CIFUENTES, 2010). Thus the ontology of visualization, as in the case of imagination and intuition, is constituted by the relations between things and not properly things. "And we see intuition, 
which must be the object of formation, exercises, to reach a level higher than directly sensitive intuitions. The high degree of development of this intuition allows the capacity to invent and to be creative" (PATY, 2010, p. 175, o.t.).

Visualization in mathematics is a form of observation and experimentation. To imagine is to observe and experience within an abstract world. And observation is always consolidated by setting standards through analogies, syntheses, and so on. It is necessary to educate the "look" to configure this mathematical experience.

Learning to "see" in mathematics is fundamental to understanding mathematics itself, and to learning to see, "one must first know that for a single mathematical object there are many ways of representing mathematics; then, a specific learning of the treatments inherent to each type of representation is necessary" (FLORES, 2007, p. 26, o.t.).

But how to visualize "things" that you can not see? In order to see them, according to Cifuentes (2013), it is required, besides the sight of the vision, the vision of the imagination. When we speak of "things," we are not referring to their physical concreteness, that is, that can be seen space-temporally, but to the abstract, "concreteness" woven in the web of relationships.

In this sense, one of the dynamic visualization forms that the imagination promotes is through analogies. As we have seen, what happens in smaller dimensions gives us arguments for visualizing one's own in larger dimensions. Thus, it is a source of knowledge in mathematics, and therefore, faced with this possibility, we seek to inquire about its pedagogical virtues. For example, in a first course in linear algebra we can ask the following "naive" question: is it possible to have two non-parallel planes intersecting at a single point? The immediate answer is "no". This would be the correct answer in our three-dimensional space, however, it can be argued that if the two planes were in a fourdimensional space, this would be plausible. To "visualize" this situation in order to make it plausible, we resort to an analogy that reveals its dynamic character in the passage from one dimension to another: is it possible that two non-parallel lines do not intersect? If both are in the two-dimensional plane, this is impossible, but if they are in threedimensional space, it is perfectly possible. An extra degree of freedom makes this situation possible.

Observation, as one of the constituents of visualization, is also at the basis of the process of mathematical modeling, a process that is so important in the act of "mathematical doing", since the elaboration of a mathematical model of some physical, 
social phenomenon, imagination, intuition and creativity, besides, of course, a lot of mathematics. To model is to observe a "piece" of the world, but not of the world as it is, because this observation is already loaded with theory, preconception, previous knowledge, therefore, observation through a mathematical model is "seeing" the interpreting it (CIFUENTES; NEGRELLI, 2012).

The new technologies also allow to observe and "see" the dynamics and the transformations of the geometric figures, favoring the intellectual manipulations of these figures. Mathematical constructions using mathematical software such as Geogebra allow curiosity to be stimulated and stimulate imagination and intuition (CIFUENTES; FRANCO, 2017). In this regard, they should be present in the training process.

For Cifuentes, the visualization

will be the main mechanism for "seeing" the truth of a mathematical result
without resort to logical demonstration. The visual demonstrations will
possibly make use of an appropriate visual language, also involving
computational means, which can highlight the artistic expressiveness of
mathematics. Every concept of visualization refers to a certain "reality", for
"reality is the basic visual experience" (2005, p. 71 , o.t.).

The creative act is intimately linked to the imagination, understood in this process as the "articulation of feelings, their transformation into images and the encounter of symbols that express these processes and results" (DUARTE JR, 1988, p. 98, o.t.). According to Duarte Jr, creative attitude is an act of rebellion, an act of courage insofar as the creator "denies the established, the existing, to propose another way, another way, finally, to propose the new. The new one arises out of a dissatisfaction with the established. In these terms any creative act is always subversive, because it aims at the modification, the modification of the existing" (1991, p. 54, o.t.).

For Ennio De Giorgi (D'AMBROSIO, 2011, o.t.), "Mathematics is the only science with the capacity to move from the observation of visible things to the imagination of things that are not visible. This is perhaps the secret of the strength of mathematics". Yet, according to D'Ambrosio (2011, o.t.), "I think that the origin of creativity in all fields is what I call the ability or willingness to dream: to imagine different worlds, different things, and to try to combine them in various ways", which brings us back to Bachelard.

Scientific activity as well as mathematical activity is creative and requires a restless and ready reason to create the new, requiring for that, to resort to imagination and intuition. Open reason is the only alternative for a science that strives to find the new. By 
"giving existence to the unreal, this reason becomes analogous to arts" (PAIVA, 2005, p. 110 , o.t.).

The exercise of creativity, made possible by intuition and imagination, can further promote a new attitude in mathematics classroom stimulating another way of understanding mathematics itself.

\section{References}

BACHELARD, G. La intuición del instante. 2nd. edition. México: Fondo de Cultura Económica, 1999.

BACHELARD, G. Estudos. Rio de Janeiro: Contraponto, 2008.

BARBOSA, E.; BULCÃO, M. Pedagogia da razão, pedagogia da imaginação. Petrópolis: Vozes, 2004.

BRUNSCHVICG, L. Las etapas de la filosofía matemática. Buenos Aires: Lautaro, 1945.

BRUTTER, C- P. Compreender as matemáticas: as dez noções fundamentais. Lisboa: Piaget Institute, 1998.

CIFUENTES, J. C. Uma via estética de acesso ao conhecimento matemático. Bulletin GEPEM, Rio de Janeiro, n. 46, p. 55-72, 2005.

CIFUENTES, J. C. Do conhecimento matemático à educação matemática: uma "odisseia espiritual”. In: CLARETO, S. M.; DETONI, A. R.; PAULO, R. M. (org.). Filosofia, Matemática e Educação Matemática: compreensões dialogadas. Juiz de Fora: Publisher UFJF, 2010. p. 13-32.

CIFUENTES, J. C. A magia de Escher (M.C. Escher): interview [08 de maio, 2013]. Curitiba: UFPR TV. Interview granted to the Caldo de Cultura Program, UFPR. Available in:

https://www.youtube.com/watch?v=H42B-OARxz0\&feature=youtu.be. Access in 16 set. 2015.

CIFUENTES, J. C. Modelagem Matemática e inclusão científica: uma abordagem históricoepistemológica. In: ALENCAR, E. S.; BUENO, S. (org.). Modelagem matemática e inclusão. São Paulo: Library of Physics Publisher, 2017, p. 1-22.

CIFUENTES, J. C.; FRANCO, V. S. O pensamento geométrico no ensino superior e o despertar da imaginação. UNIÓN - Ibero-American Journal of Mathematics Education, Montevideo, n. 50, p. 9-28, aug. 2017.

CIFUENTES, J. C.; NEGRELLI, L. G. Uma interpretação epistemológica do processo de modelagem matemática: implicações para a matemática. BOLEMA, Rio Claro, v. 26, n. 43, p. 19-43, aug. 2012.

D’AMBROSIO, U. Priorizar história e filosofia da matemática na educação. In: CONFERÊNCIA INTERAMERICANA DE EDUCAÇÃO MATEMÁTICA, 13, 2011, Recife. Anais... Recife, 2011. Published on CD-ROM.

DUARTE JUNIOR, J. F. Fundamentos estéticos da educação. 2nd. edition. Campinas: Papirus, 1988. 
DUARTE JUNIOR, J. F. Por que arte-educação? 6th. edition. Campinas: Papirus, 1991.

FLORES, C. Olhar, saber, representar: sobre a representação em perspectiva. São Paulo: Musa, 2007.

GUSMÃO, L. D. A Elaboração de uma Epistemologia da Intuição e da Imaginação no Campo da Matemática e Implicações para a Educação Matemática: diálogos com Henri Poincaré e Gaston Bachelard. 2018. Thesis (Doctorate in Education for Science and Mathematics) - State University of Maringá, Maringá, 2018.

GUSMÃO, L. D.; FRANCO, V. S.; CIFUENTES, J. C. A imaginação e a intuição na dinâmica do conhecimento matemático: subsídios para uma pesquisa epistemológica e pedagógica.

Perspectivas da Educação Matemática, Campo Grande, v. 10, n. 22, p. 366-387. 2017.

HUNTLEY, H. F. A divina proporção. Brasília: Publisher UnB, 1985.

OSTROWER, F. Criatividade e processos de criação. Petrópolis: Vozes, 2010.

PAIVA, R. Gaston Bachelard: a imaginação na ciência, na poética e na sociologia. São Paulo: FAPESP, 2005.

PATY, M. Pensamento racional e criação científica em Poincaré. Scientiae Studia, São Paulo, v. 8 , n. 2, p. 177-193. 2010.

POINCARÉ, H. O valor da ciência. Rio de Janeiro: Contraponto, 1995.

POINCARÉ, H. Ensaios fundamentais. Videira, A. P.; Moreira, I. (org.). Rio de Janeiro: Contraponto, 2008.

PÓLYA, G. Matemáticas y razonamiento plausible. Madrid: Tecnos, 1966.

TORRES ALCARAZ, C. Kant visto desde las matemáticas. Revista Digital Universitária.

Cidade do México, v. 6, n. 1, p. 1-21, jan. 2005.

Received in: August 08, 2020.

Accepted on: September 15, 2020. 